\title{
SOLUÇÕES DE GERENCIAMENTO TÉRMICO PARA REDUÇÃO DO CONSUMO DE COMBUSTÍVEL EM VEÍCULOS COMERCIAIS
}

\author{
Edison Tsutomu Miyauchi ${ }^{1}$, Renon Queiroz De Lima ${ }^{1}$ e Diego Pivatto Erberelli ${ }^{1}$ \\ ${ }^{1}$ Mahle Behr Gerenciamento Térmico Brasil Ltda. \\ E-mails: edison.miyauchi@br.mahle.com, renon.lima@br.mahle.com, \\ diego.erberelli@br.mahle.com
}

\section{RESUMO}

Ao longo dos últimos anos, o atendimento da legislação de emissões cada vez mais rigorosa tem sido o foco para o desenvolvimento de motores de veículos comerciais. $\mathrm{O}$ desenvolvimento de soluções técnicas que levam a redução do consumo de combustível tornou-se também de extrema importância na área.

O gerenciamento térmico nos motores irá desempenhar um papel importante para atender as futuras demandas de redução de consumo de combustível. Com o aumento da demanda térmica dos motores, combinado com o restrito espaço disponível no compartimento, faz-se necessários trocadores de calor de maior eficiência, que ainda assim irão requerer uma maior vazão de ar no sistema.

Soluções de sistemas de arrefecimento, ventiladores e bombas d'água combinadas a embreagens viscosa de acionamento eletrônico são exemplos de produtos que auxiliam no atendimento de tais demandas.

Resultados de simulações e testes serão apresentados de forma a ilustrar o potencial destas tecnologias.

\section{INTRODUÇÃO}

As leis de emissões continuarão sendo o direcionador da tecnologia no segmento de veículos comerciais. Em 2012 iniciou-se no Brasil a legislação Proconve P7, o equivalente ao Euro V na Europa, o que pressionou os fabricantes de veículos comerciais e toda a sua cadeia de fornecedores a viabilizarem soluções tecnológicas mais avançadas para os motores e seus periféricos. Os avanços continuarão a acontecer. Com a legislação Euro V já em vigor desde 2008, a União Europeia já está recebendo em 2014 a fase Euro VI [1] do programa de controle de emissões. Mas um ano antes, em 2013, os principais fabricantes de caminhões europeus já tinham adequado as tecnologias dos novos projetos para as demandas do Euro VI. Comparada ao Euro V, esta nova fase restringe ainda mais os gases de emissão e as quantidades de particulados. A introdução do Euro VI no Brasil ainda é um tema ainda em discussão e sem data concreta de implementação, mas desde já os fabricantes e seus fornecedores estão se preparando para a próxima fase que certamente virá. O Brasil é responsável por $3,5 \%$ das mortes prematuras mundiais causadas pela exposição às emissões de partículas de veículos urbanos, e por cerca de 30\% na América Latina [2]. 
Por sua vez, segmento dos veículos comerciais médios e pesados voltam agora as atenções para outro parâmetro importante: o consumo de combustível. Impulsionado por preocupações sobre o aquecimento global, a necessidade de proteger os limitados recursos de combustíveis fósseis, ou simplesmente pela necessidade de reduzir os custos operacionais dos veículos, a redução do consumo de combustível do veículo, e consequentemente, das emissões de $\mathrm{CO}_{2}$, vai se tornar o foco. Assim, espera-se que as legislações para limitar a emissão de $\mathrm{CO}_{2}$ de veículos comerciais serão os direcionadores das tecnologias dos próximos anos. Com isso, haverá forte direcionamento de tecnologia para essa redução.

Neste contexto, o gerenciamento térmico nos motores torna-se de grande importância, uma vez que as soluções técnicas para atingir as já rigorosas leis de emissão existentes irão requer sistemas de arrefecimento cada vez mais eficientes e com maior potencia de dissipação térmica, que por sua vez irão requerer soluções de ventiladores e bombas mais potentes. Por outro lado, para compensar o aumento de energia causado por esse aumento de potência nos seus acionamentos, serão necessárias soluções de controles inteligentes que atuem apenas quando demandado, e que eliminem as perdas de energia quando desnecessárias. A preocupação com a demanda de energia não era um fator considerado fundamental no dimensionamento das soluções existentes até o presente momento. Com a nova legislação o endereçamento de tais demandas passa a ser fundamental.

O objetivo deste artigo é destacar as alternativas tecnológicas que proporcionam a efetiva redução do consumo de combustível e que estão relacionadas ao gerenciamento térmico. Primeiramente é apresentada uma avaliação do impacto das demandas legais nos sistemas de arrefecimento motor. Nas seções seguintes discorremos sobre alternativas tecnológicas possíveis ao gerenciamento térmico e relacionadas à geração e gerenciamento do fluxo de ar, necessário para a convecção forçada, e à geração e gerenciamento do fluxo de refrigerante.

\section{IMPACTO DAS LEIS DE EMISSÕES NOS SISTEMAS DE ARREFECIMENTO}

A introdução da legislação EuroVI na Europa confirmou a tendência técnica em que a maioria das soluções se utilizam da combinação de refrigeradores de gás de exaustão EGR (Exhaust Gas Recirculation) com sistema de pós-tratamento SCR (Selective Catalytic Reduction). Isto implica geralmente em requisitos mais rigorosos para o sistema de arrefecimento, que em termos de impactos são [3]:

- Altas temperaturas e pressões no sistema de refrigeração

Os radiadores têm de suportar maiores cargas. As pressões no sistema de arrefecimento são aumentadas devido às bombas mais potentes, temperaturas mais altas e mudanças nas arquiteturas de circuito.

- Aumento da quantidade de calor que o sistema de arrefecimento tem de rejeitar Os novos refrigeradores EGR tem de rejeitar adicionalmente até 100kW [3] [4] que são transferidos do sistema de arrefecimento para o ar ambiente. As quantidades necessárias de ar de refrigeração deverão ser fornecidas por novos ventiladores, os quais, por sua vez, necessitam de novos sistemas de acionamento do ventilador. 
- Temperaturas do ar de admissão e pressões mais elevadas

O uso de EGR implica em pressões mais elevadas de até 4,0bar, que anteriormente eram até aproximadamente $3,5 \mathrm{bar}$; e temperaturas de até $240^{\circ} \mathrm{C}$, que anteriormente eram de até aproximadamente $200^{\circ} \mathrm{C}$. Isto resulta numa carga adicional sobre o trocador de calor do ar de admissão - CAC (Charge Air Cooler).

- Circuito de arrefecimento de baixa temperatura

As rigorosas especificações de arrefecimento necessárias nos CAC's e EGR's em muitos arranjos já requerem sistemas com 2 estágios, dotados de circuitos secundários com uso de fluído à baixa temperatura que utilizam novos radiadores de baixa temperatura.

- Evitar o consumo de combustível adicional

A necessidade de maior fluxo do fluído de arrefecimento e também do ar de refrigeração nos módulos de arrefecimento exige bombas e ventiladores mais potentes. O consumo de combustível adicional devido a este aumento de potência pode ser evitado pela adoção de um controle racional de fornecimento de fluido e ar, que proporciona a satisfação da demanda somente quando ela acontece, sem a necessidade de operar sempre na máxima.

Levando-se em conta os impactos acima citados para o sistema de arrefecimento, é pouco provável que os valores limites de emissões muito mais baixos do Euro VI possam ser atingidos sem um aumento do consumo de combustível, em relação aos sistemas preparados até o Euro V. Para mantermos este adicional de consumo ao mínimo, é necessário que os sistemas de arrefecimento sejam mais eficientes, através do uso de novos componentes, e que tenha uma otimização na sua interação. Esta otimização nos sistemas de arrefecimento como um todo é chave para implementação de novas tecnologias para reduzir o consumo de combustível.

A seguir são apresentadas as evoluções e novas aplicações de um importante componente que faz parte do sistema de arrefecimento [3] e que suportam soluções de redução de consumo de combustível, as embreagens viscosas, chamadas de agora em diante por Visco ${ }^{\circledR}$.

\section{EMBREAGENS VISCOSAS PARA VENTILADORES E BOMBAS D’ÁGUA}

Para atender as demandas rigorosas das futuras leis de emissões é esperado que sistemas atuais puramente baseados na tecnologia SCR necessitem ser suplementados com a tecnologia EGR, conforme ilustrado na figura 1. Isto aumenta a quantidade de calor a ser dissipada nos sistemas de arrefecimento, resultando em 15 a $20 \%$ adicionais de vazão de ar refrigerante necessária no sistema. Para atender estas demandas, novas gerações de embreagens viscosas eletrônicamente controladas foram desenvolvidas, e hélices de ventiladores também foram otimizadas. 


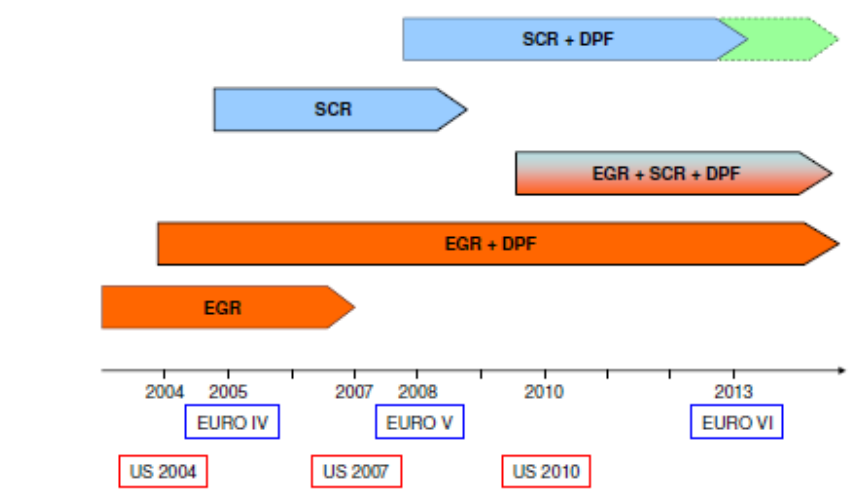

Figura 1 - Resumo das tecnologias para a redução de emissões em veículos pesados movidos a Diesel [4]

Um outro campo de aplicação da embreagem viscosa é na bomba d'água. As bombas d'água são usualmente diretamente ligadas ao eixo do motor através de um jogo especifico de polias sem um próprio controle de acionamento. Com a implementação de uma embreagem viscosa eletrônicamente controlada, a circulação do fluxo de fluído de arrefecimento pode ser controlada de acordo com a necessidade específica da condição de operação em que se encontra.

O acionamento dos ventiladores devem ser variáveis.

Fundamentalmente, a maior parte do calor gerado nos motores de combustão interna pode ser transferida somente para o ar de arrefecimento. Quando a pressão dinâmica resultante da velocidade do veículo não é mais suficiente para fazer o ar fluir através dos trocadores de calor e para fora do compartimento do motor para dissipar o calor, os ventiladores são os responsáveis por fornecer a pressão adicional requerida. Como a potência necessária para atender a máxima vazão de ar requerida pode chegar a até $40 \mathrm{~kW}$, esta potência necessita ser suplida pelo virabrequim do motor. Para este nível de potência, os motores elétricos usualmente utilizados em veículos de passeios não são suficientes. Porém, a mesma controlabilidade de ajuste da velocidade das hélices, como acontece com os motores elétricos, é desejada para que seja fornecida a quantidade exata de vazão requerida. Qualquer fornecimento de vazão de ar em excesso resulta em um consumo de combustivel e emissão de ruídos desnecessários.

Princípio do Visco: transmissão de torque através da fricção de cisalhamento

A mais avançada embreagem variável para veículo comerciais é a embreagem eletronicamente controlada, abreviada de E-Visco ${ }^{\circledR}$. Com o princípio do Visco ${ }^{\circledR}$, o torque é transferido do virabrequim para o ventilador através da fricção de cisalhamento de um fluido específico que se encontra no interior da embreagem.

Estrutura de uma embreagem E-Visco

A figura 2 mostra a seção de uma embreagem E-Visco ${ }^{\circledR}$. O lado de entrada (primário), que consiste do eixo e do disco primário, ambos rigidamente conectados, é alimentado pela rotação do virabrequim do motor. O lado de arraste (secundário) é composto de um corpo, que envolve o disco primário, e pelo ventilador que é conectado a este corpo e têm a rotação de arraste. O solenóide permanece fixo, facilitando a conexão elétrica da embreagem e do controlador do motor. 


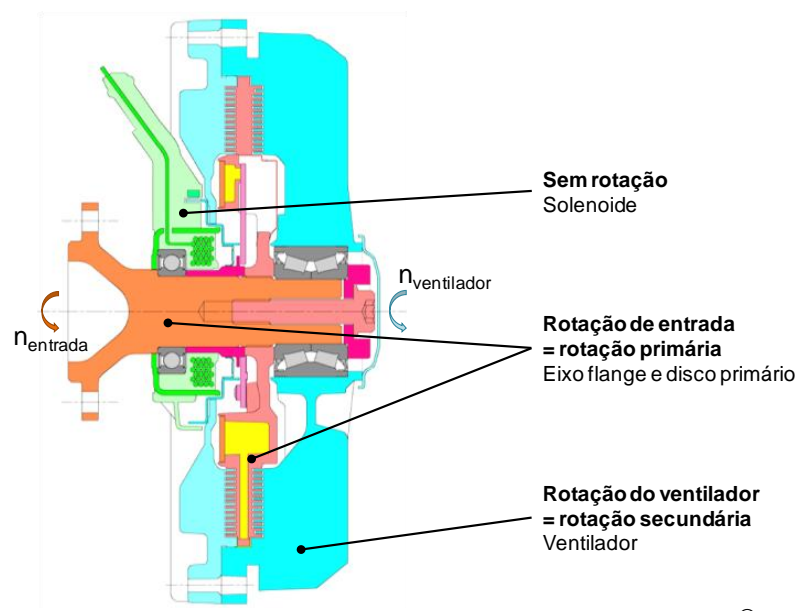

Figura 2 - Secção de uma embreagem E-Visco ${ }^{\circledR}$

\section{Controle de rotação variável contínua}

O controle de velocidade é mostrado na figura 3. No estado (1), a abertura do orifício da câmara reservatório do disco primário, que contêm o óleo silicone, é mantida fechada pela válvula. Apesar de existir uma rotação de entrada, nenhum torque é transferido para o lado secundário. A embreagem está desacoplada, ou em iddle, apenas com a baixa rotação resultante do atrito de arrasto do rolamento.

No estado (2), com a abertura temporaria do orifício, a força centrífuga direciona o óleo silicone para a câmara de trabalho. Com o enchimento do óleo nos pequenos espaços existentes entre o disco primário e a corpo da embreagem, ocorre então a transmissão de torque devido á fricção de cisalhamento do óleo. A diferença de rotação que sempre ocorre entre o disco primário e o corpo é usada para gerar uma pressão estática através de um perfil específico na circunferência externa do disco primário, que bombeia o óleo de volta para a câmara reservatório por um orifício de retorno. Dependendo de quanto a válvula está aberta, a câmara de trabalho pode ser preenchida em diferentes níveis, resultando em velocidade de ventilador entre iddle (1) até o acoplamento total (3). Em (3), o ventilador atinge rotação próxima da entrada, apresentando apenas um pequeno escorregamento.

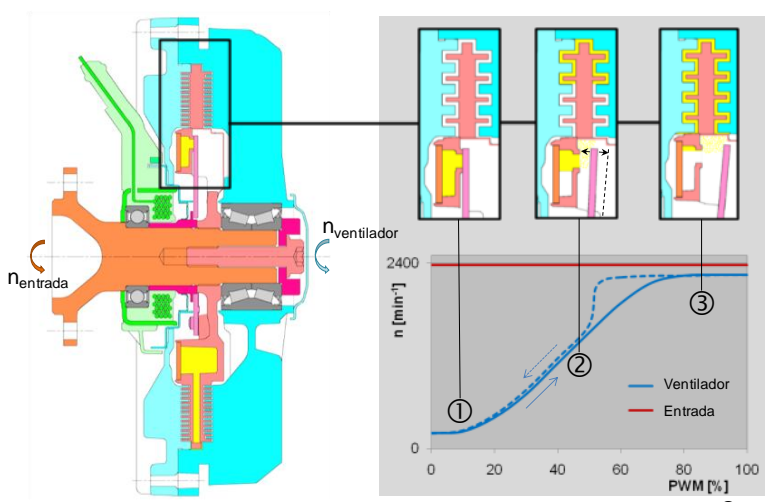

Figura 3 - Operação de uma embreagem E-Visco ${ }^{\circledR}$

O grau de abertura da válvula é controlado por um campo magnético pulsante gerado por um solenoide. A alavanca fecha quando o campo magnético estiver 'ligado', e abre quando estiver 'desligado'. O grau de abertura depende das proporções entre o tempo em que o campo magnético estiver ligado e desligado. Um campo magnético contínuo fecha a alavanca da 
válvula totalmente, de modo que o líquido é drenado para a câmara reservatório, e a embreagem entra em estado de iddle. Se o campo magnético estiver sempre desligado, a alavanca de válvula é aberta completamente, então mais fluído é introduzido na câmara de trabalho do que drenado pelo disco primário, e a embreagem fica completamente acoplada. Este é também um dispositivo à prova de falhas, garantindo que o ventilador esteja completamente acoplado e que se tenha capacidade de arrefecimento completa, quando o fornecimento de energia elétrica para o solenóide é interrompido.

O sistema de controle do motor inclui um programa software que solicita uma determinada velocidade do ventilador com base em parâmetros como temperatura do líquido refrigerante, temperatura do ar no turbo compressor, ar condicionado de cabine, ou operação do retarder (sistema de freio motor). A velocidade real do ventilador é registrada por um sensor integrado no solenoide e o resultado reportado ao sistema de controle do motor, fechando assim o ciclo de controle. Com este controle a rotação necessária é alcançada rápida e linearmente, e é em seguida mantida a um nível constante. Estes são critérios importantes para um sistema preciso de regulagem.

$\underline{\text { O que se entende por arrefecimento sob demanda? }}$

Para responder esta pergunta, primeiro precisamos olhar para os diferentes modos de operação, ou seja, o espectro de carga para um motor de veículo comercial de longa distância, figura 4. O tamanho dos círculos nesta ilustração mostra a frequência com que o caminhão é conduzido a uma velocidade e carga especifica correspondente. Além da marcha lenta de 600rpm, predominam cargas médias em torno de 1400 e 1500rpm, típico para operação em estrada a uma velocidade de cerca de $80 \mathrm{Km} / \mathrm{h}$.

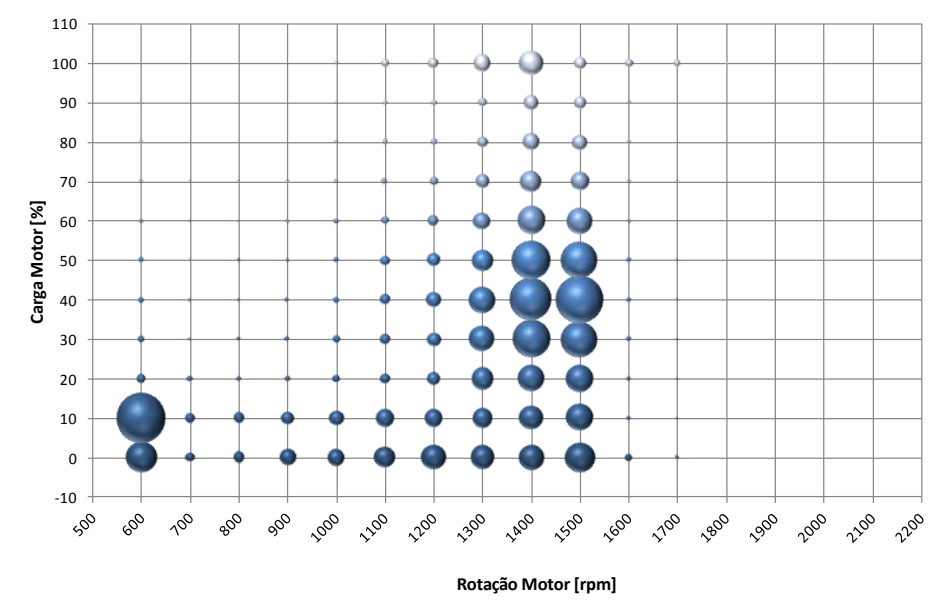

Figura 4 - Espectro de carga de um caminhão de longa distância

Analisando agora os tipos de controle de rotação do ventilador, temos em cada um dos três diagramas da figura 5, um diagrama para cada modo de controle do ventilador, foram introduzidas as áreas de velocidades necessárias dos ventiladores para todas as condições de operação, derivado do mapa de funcionamento do motor. A linha diagonal representa as velocidades máximas possíveis do ventilador. Comparando-se as áreas dos pontos de operação necessária do ventilador com os pontos de operação que podem ser alcançados por estes diferentes modos de controle, fica claro que um ventilador rigidamente acoplado diretamente à velocidade do motor atua em velocidades muito mais altas que o necessário. 
Observa-se que mesmo com um ventilador equipado com uma unidade on/off, ainda não se tem um processo de refrigeração ideal. Somente um controle de velocidade continuamente variável de um E-Visco permite que cada ponto de funcionamento do ventilador seja corretamente configurado.

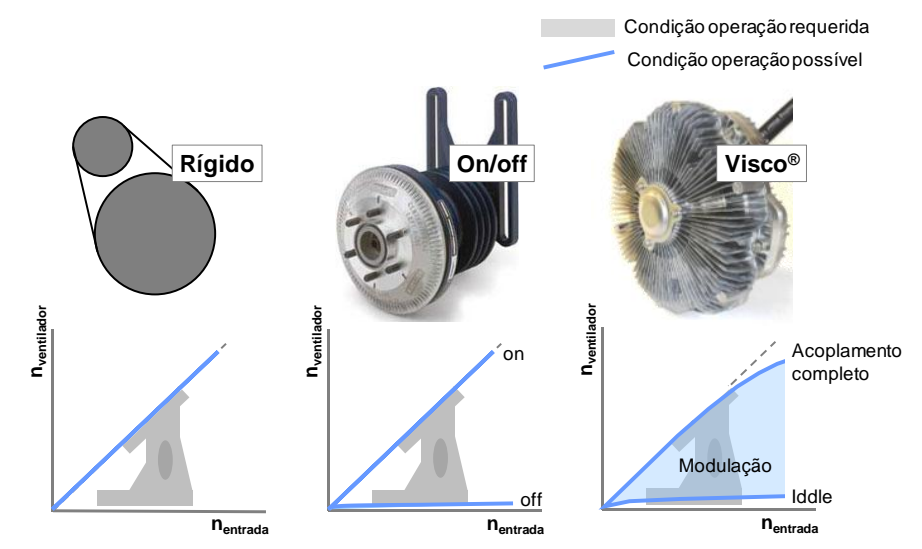

Figura 5 - Condição de operação requerida do ventilador x possíveis,

por tipo de acionamento

Logicamente, a potência de acionamento do ventilador irá depender do tamanho e do desempenho dos trocadores de calor e a resistência (estrangulamento) do compartimento do motor ao ar refrigerante. Em situações que facilitam resfriamento (trocadores de calor eficientes e pouco estrangulamento do ar no compartimento), o resfriamento devido a corrente de ar é muitas vezes o suficiente, sem necessidade de qualquer assistência do ventilador. No entanto, uma vez que a tendência dos veículos é de maior estrangulamento no compartimento do motor e trocadores de calor com menores áreas frontal, um número crescente de veículos estão sendo equipados com unidades E-Visco ${ }^{\circledR}$ continuamente variáveis.

Arrefecimento preciso com embreagens E-Visco ${ }^{\circledR}$

A figura 6 mostra a diferença de um controle oscilante on/off e um controle preciso utilizando uma embreagem E-Visco ${ }^{\circledR}$. Com o controle on/off, a unidade mantém-se desacoplado até que a temperatura do líquido de arrefecimento é superior ao limiar admissível. O ventilador é então completamente acoplado, o qual, no entanto, causa um arrefecimento excessivo. $\mathrm{O}$ ventilador é desacoplado novamente após um curto período de tempo, e segue-se uma fase de pouco arrefecimento no sistema. Apesar da velocidade do motor constante, as temperaturas dos fluidos que precisam ser resfriados (em especial, o líquido de arrefecimento e o ar de admissão) e as cargas colocadas nos trocadores de calor e da própria unidade do ventilador estão sujeitos a flutuações extremas. 

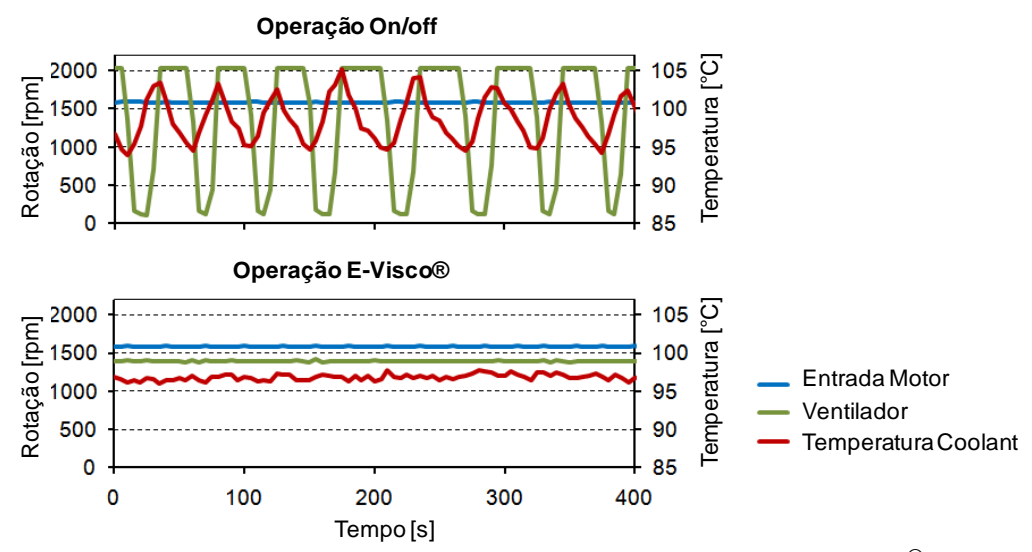

Figura 6 - Comparativo de um controle on/off e um E-Visco ${ }^{\circledR}$

No caso da embreagem E-Visco ${ }^{\circledR}$, tais flutuações são eliminadas e a solicitação sobre os trocadores de calor e acionamentos por correia também é reduzida. A unidade E-Visco ${ }^{\circledR}$ não requer manutenção, enquanto uma unidade on/off requer manutenção regular, devido aos frequentes impulsos de comutação.

Simulações mostram que, quando usado em aplicação de transporte de longas distâncias, a embreagem E-Visco ${ }^{\circledR}$ necessita de uma potência de acionamento muito menor do que uma unidade on/off em todas as condições de carga, com exceção na baixa carga (até cerca de 25\%). É verdade que a unidade on/off não precisa ser acionado em condições de baixa carga do motor, mas assim que é exigida o seu acionamento, será necessário uma potência de acionamento muito maior nas cargas médias. Isto resulta em menor consumo de combustível com o E-Visco ${ }^{\circledR}$, como ilustrado na figura 7. O E-Visco ${ }^{\circledR}$ é menos eficiente apenas em baixa carga, uma vez que, diferentemente da unidade on/off, ele sempre opera em baixa velocidade (iddle) de arraste quando a unidade está na condição desacoplada. Mas levando em conta todo o espectro de cargas típicas de um veículo de transporte de longa distância, a unidade EVisco ${ }^{\circledR}$ apresenta uma melhoria de $0,7 \%$ em termos de consumo de combustível. E se comparado com um acionamento do tipo rígido, onde o ventilador está sempre na mesma rotação do motor, a melhoria é de até $4 \%$.

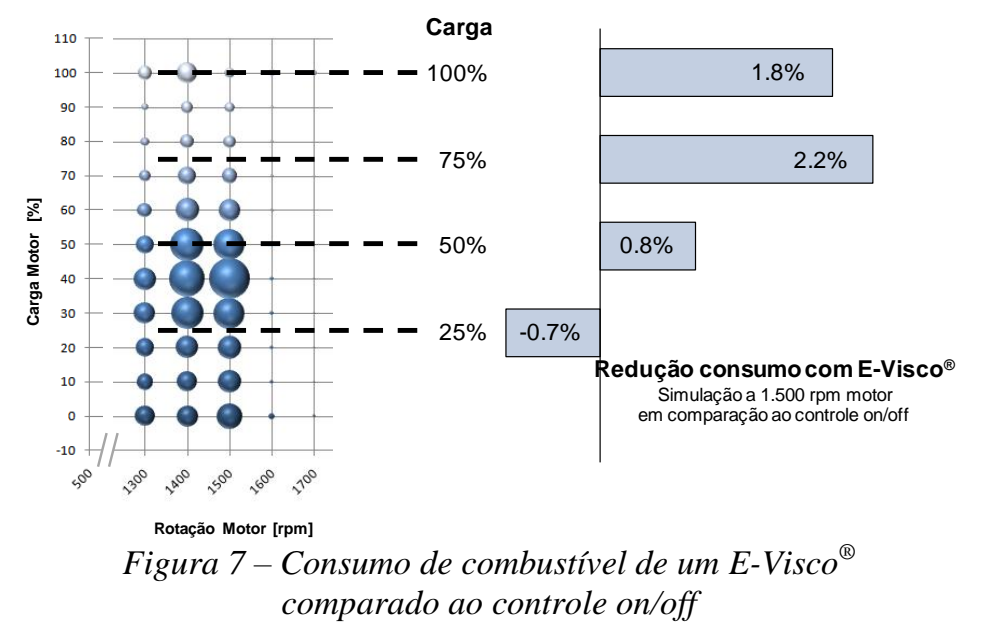




\section{Bomba d'água com acionamento viscoso}

A introdução das embreagens viscosas em ventiladores com controle de variação contínua trouxe uma importante contribuição para a economia de combustível para os veículos comerciais. A implementação do conceito de embreagem viscosa para bomba d'água [5], permite agora para este componente que é parte integrada do motor, uma adaptação ideal para atender os requisitos de redução da potência de acionamento.

\section{Redução da potência de acionamento}

Bombas de água atualmente estão equipadas quase exclusivamente por acoplamento direto no motor, o que resulta em um fluxo elevado de fluido desnecessário em muitas condições de funcionamento. Esse potencial de redução do fluxo e potência de acionamento é atingido pela bomba d'água com embreagem viscosa. Cada vez mais a demanda por redução do consumo de combustível em veículos comerciais tem se tornado mais rigorosa e uma forte motivação para o desenvolvimento de potenciais para redução. Uma área importante para medidas que podem ser tomadas para tal economia de combustível é referente ao consumo de energia dos sistemas auxiliares do motor. Na área de arrefecimento do motor, já na última década, foi possível atingir um potencial considerável pela evolução da tecnologia de acionamento do ventilador de uma embreagem viscosa bimetálica para uma eletronicamente controlada. Uma vez que o completo acoplamento do ventilador é necessário apenas por uma pequena porcentagem de tempo. As maiores economias foram atingidas no aumento do tempo em que o ventilador está desacoplado e pelo rápido acoplamento somente quando a temperatura do líquido de arrefecimento atinge altas temperaturas.

O próximo passo seria a otimização dos componentes individuais. Já existem progressos consideráveis nas bombas d'água no que se refere ao desenvolvimento das lâminas do rotor. Isto fez com que eficiências hidráulicas maiores que $60 \%$ já sejam uma realidade. Porém, os maiores potenciais de redução podem ser identificados em função do controle inteligente de tais componentes. Antes do lançamento do Euro V, as bombas de água usualmente eram de conceitos exclusivamente rígidos, acionado diretamente por correias ligadas ao virabrequim. Uma vez que o fluxo de vazão da bomba de água geralmente é projetado para a condição de operação mais critica, todos os outros pontos de operação são ou apresentam potencial de redução.

Em uma bomba d'água o fluxo aumenta quase que linearmente com o aumento da rotação, entretanto o consumo de energia aumenta na terceira potência. Isto significa que se em um determinado ponto de operação houver uma redução do fluxo para metade do máximo projetado, a potência necessária para o acionamento é reduzido a um oitavo. Portanto, a rotação da bomba é um parâmetro importante na redução da potência de acionamento.

\section{$\underline{\text { A seleção do conceito técnico }}$}

Na figura 8 temos uma comparação do potencial teórico de redução de potência dos vários conceitos, com base numa velocidade frequentemente utilizada em um motor para veículos comerciais pesados (1200rpm). De um lado tem-se como base o conceito rígido, e por outro lado, a transmissão continuamente variável que seria o ideal teórico com eficiência de $100 \%$. A embreagem viscosa é o mais próximo da linha ideal. A diferença para a transmissão continuamente variável ideal é devido ao escorregamento. Outro conceito é o da restrição de 
saída (estrangulamento), onde a vazão é controlada pela saída do fluxo. Neste conceito, é possível reduzir a potência de acionamento na melhor das hipóteses linearmente com o fluxo, de modo que se o fluxo for reduzido pela metade, a potência de acionamento também reduziria pela metade. No conceito de duas fases, a operação em baixo fluxo só é possível quando a quantidade necessária de fluxo não exceder este baixo fluxo. Um pequeno aumento da demanda do motor faz com que a operação se eleve rapidamente ao patamar máximo de operação. A rápida troca destas fases não é desejável, uma vez que levaria a um grande aumento de pressão cíclica dos componentes do circuito de refrigeração. Tal efeito também é minimizado em uma bomba com embreagem viscosa, uma vez que o acoplamento ocorre de forma gradual.

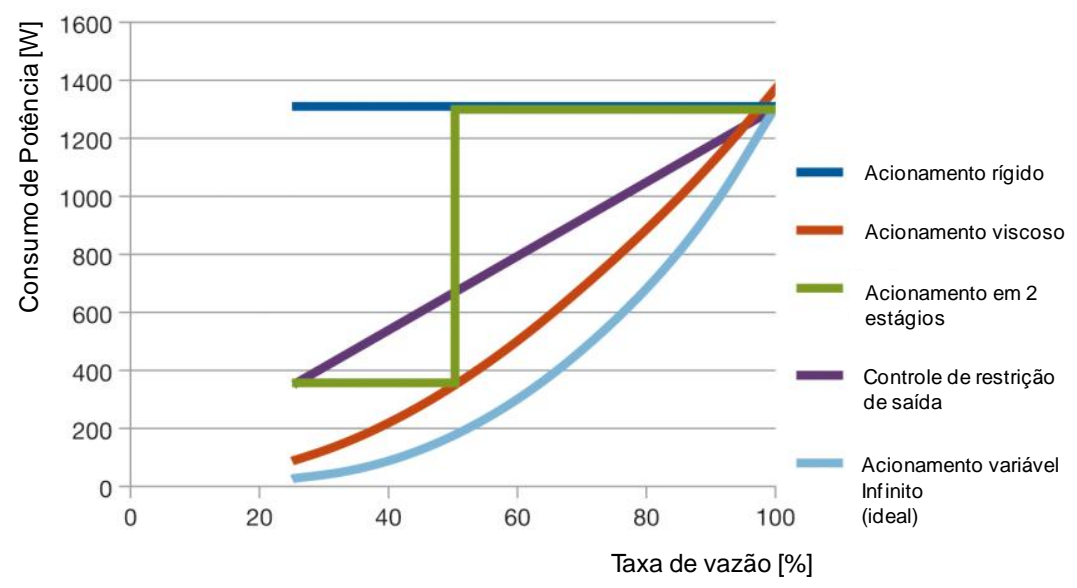

Figura 8-Comparativo dos diferentes controles de fluxo

Implementação técnica do conceito

A bomba d'água com embreagem viscosa da figura 9, pode em princípio ser disposta no mesmo espaço de uma bomba rígida. No lado da água, não são necessárias alterações, e a unidade de controle pode ser integrada na polia. Uma vez que a velocidade do rotor e da polia é diferente, faz-se necessário um rolamento duplo integrado entre eles. Um eixo central tem em uma extremidade o rotor e na outra extremidade o disco primário, de onde é feita o acionamento da bomba. $\mathrm{O}$ torque para o rotor é transmitido através de óleo silicone pela área entre o corpo e o disco primário, através da fricção de cisalhamento. De acordo com o nível de preenchimento de óleo silicone, o grau de acoplamento pode ser controlado através de uma válvula de solenoide entre as duas câmaras. A válvula, controlada por sinal PWM, é acionado por um campo magnético criado pela bobina montada sobre a caixa de rolamento. Quando a bobina está sem corrente, portanto sem campo magnético, a válvula assume a posição aberta devido ao seu efeito mola, o óleo silicone então é direcionado para dentro da câmara de trabalho efetuando assim o acoplamento do rotor. Desta maneira o modo de segurança contra falha elétrica é assegurada: o rotor gira na condição de máximo acoplamento. 


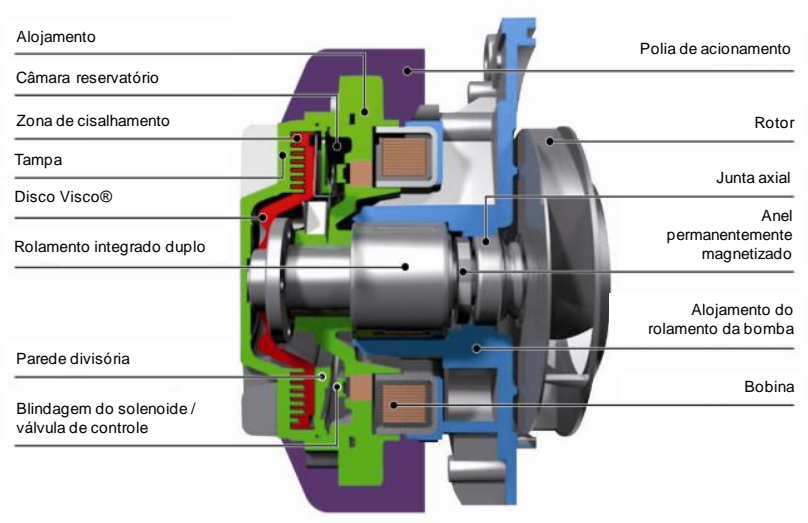

Figura 9 - Componentes de uma bomba viscosa

O controle da rotação do rotor é realizado em um circuito fechado, conforme figura 10 . Um sensor de detecção da velocidade de rotação do rotor é montado no alojamento do rolamento da bomba. Este sensor detecta os impulsos de um anel magnetizado montado no eixo do rotor. A velocidade de rotação real detectado do rotor é comparada na unidade de controle com a velocidade desejada. O sinal PWM para a unidade de controle é alterado de acordo com o desvio encontrado a fim de minimizá-lo. A detecção da velocidade real do rotor também é um parâmetro importante para a manutenção da segurança operacional do motor. Quando a velocidade é muito lenta, a potência do motor tem de ser limitado e avisos apropriados devem ser comunicados ao motorista.

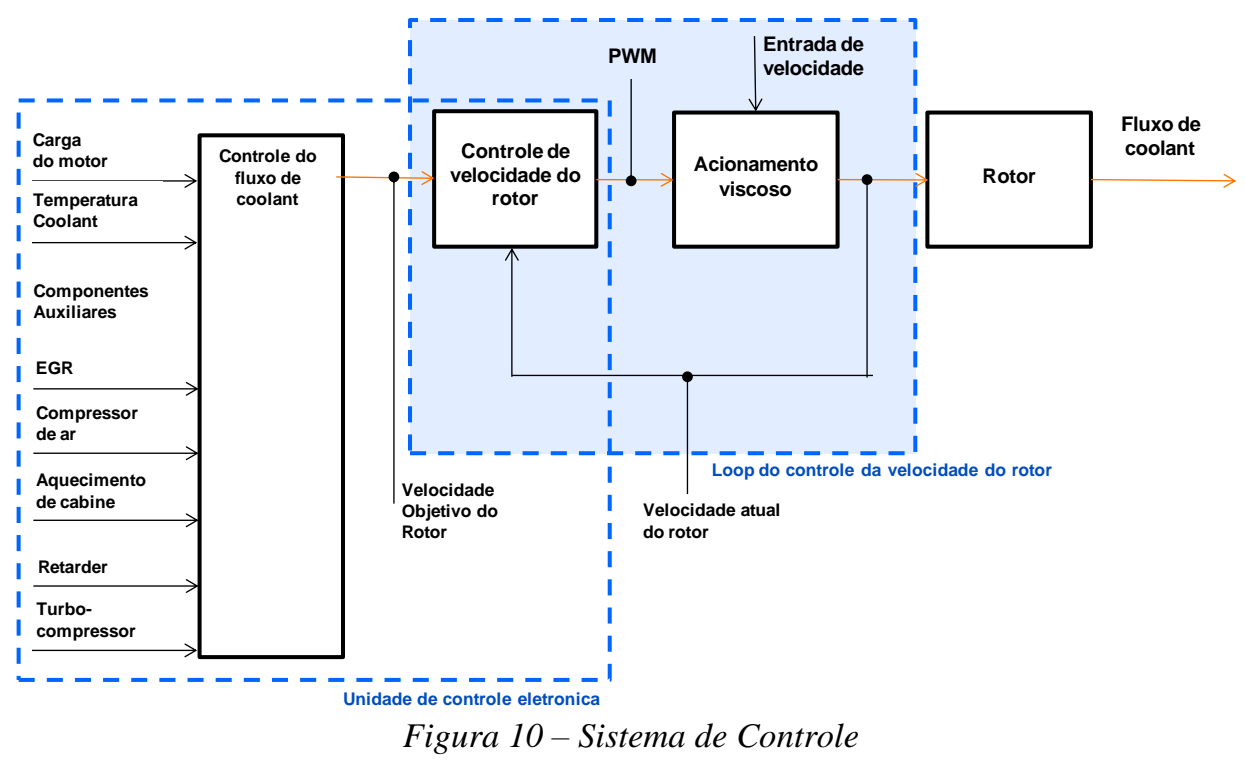

A velocidade do rotor é definida em uma unidade de controle, que depende de vários parâmetros do motor e do veículo. O principal parâmetro é o valor da carga do motor, que está associado com a quantidade liberada de calor. Além disso, outro parâmetro importante é o nível de temperatura do líquido de arrefecimento. Ainda, diversos componentes secundários como refrigerador de gás de escape (EGR), o compressor de ar para sistema de freios ou o retarder - podem requerer um fluxo específico do controle de vazão. 
Dinâmica de controle

Os requisitos específicos do veículo referente a quantidade de refrigeração para um motor apresenta diferentes comportamentos dinâmicos. A liberação de calor em pontos específicos de um motor em carga máxima, que é equipado com resfriador de gás de exaustão (EGR), podem atingir valores elevados de temperatura do líquido de arrefecimento. Para evitar a ebulição localizada do líquido de arrefecimento, o fluxo deve ser aumentado rapidamente. Estudos têm mostrado que a dinâmica de acionamento de uma bomba de água de embreagem viscosa atende estas condições. O tempo de acionamento depende da rotação de entrada e da rotação de saída em que se encontra no momento do aumento. O tempo necessário para se atingir $50 \%$ da rotação requerida é até $1 \mathrm{~s}$, e para se atingir $90 \%$ em até $4 \mathrm{~s}$. Medições em veículos mostram um bom comportamento de monitoramento da velocidade real do rotor em relação à velocidade desejada.

\section{$\underline{\text { A economia de combustível }}$}

Assumindo um mapa de operação usual do motor de um veículo comercial pesado de longas distâncias, e uma distribuição conservadora do grau de acoplamento devido à carga solicitada no motor, observamos que predominam operações em regiões de rotação entre 1000rpm e $1400 \mathrm{rpm}$, e carga de motor entre $25 \%$ a $50 \%$. Considerando o tempo de acoplamento somente quando a vazão máxima nominal é necessária, em comparação a um acionamento rígido, calcula-se uma redução da energia de acionamento de $70 \%$ - de $1,4 \mathrm{~kW}$ para $0,4 \mathrm{~kW}$. (figura 11). Considerando que um caminhão de peso total de 40 ton requer cerca de $100 \mathrm{~kW}$ de potência do motor para ser conduzido e vencer as resistências, principalmente resistência do ar e arraste dos rolamentos, a uma velocidade de $80 \mathrm{~km} / \mathrm{h}$ em um superfície plana. A redução da potência de acionamento da bomba de $1 \mathrm{~kW}$ para uma potência do motor de $100 \mathrm{~kW}$ temse, portanto, uma correspondente economia de combustível de $1 \%$.

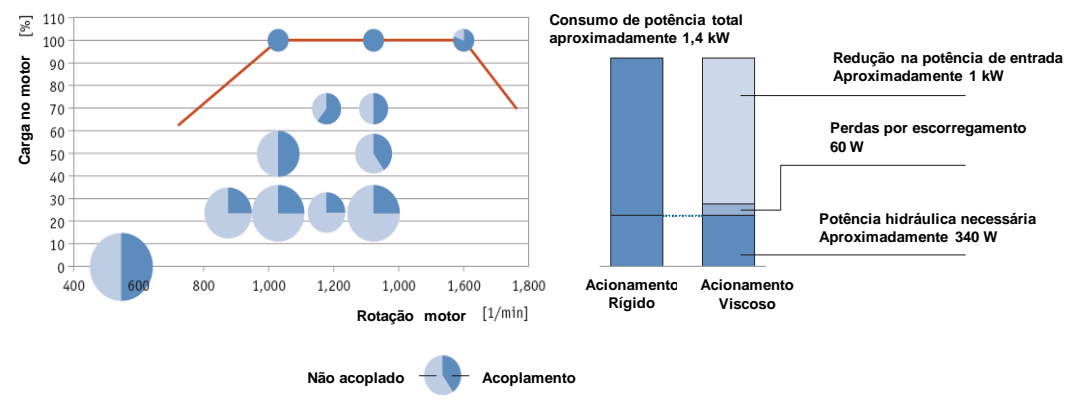

Figura 11 - Potencial de redução de consumo

Divisão dos tempos de acoplamento em cada condição de operação (Ciclo WHSC)

Este valor é fortemente dependente do perfil de operação do veículo, ou seja, da rotação específica do motor e da carga. Se considerarmos, em vez do tráfego de longa distância, que oferece as melhores oportunidades para a regulagem da bomba de água, mas, por exemplo, um caso de uso em uma região montanhosa com períodos elevados em plena carga e de frenagem, o tempo de acionamento da bomba é maior. No entanto, o potencial de redução comparada a uma tecnologia de acionamento convencional ainda é pelo menos de $0,5 \%$. Estes valores também foram confirmados a partir de testes de campo em veículos (figura 12). 

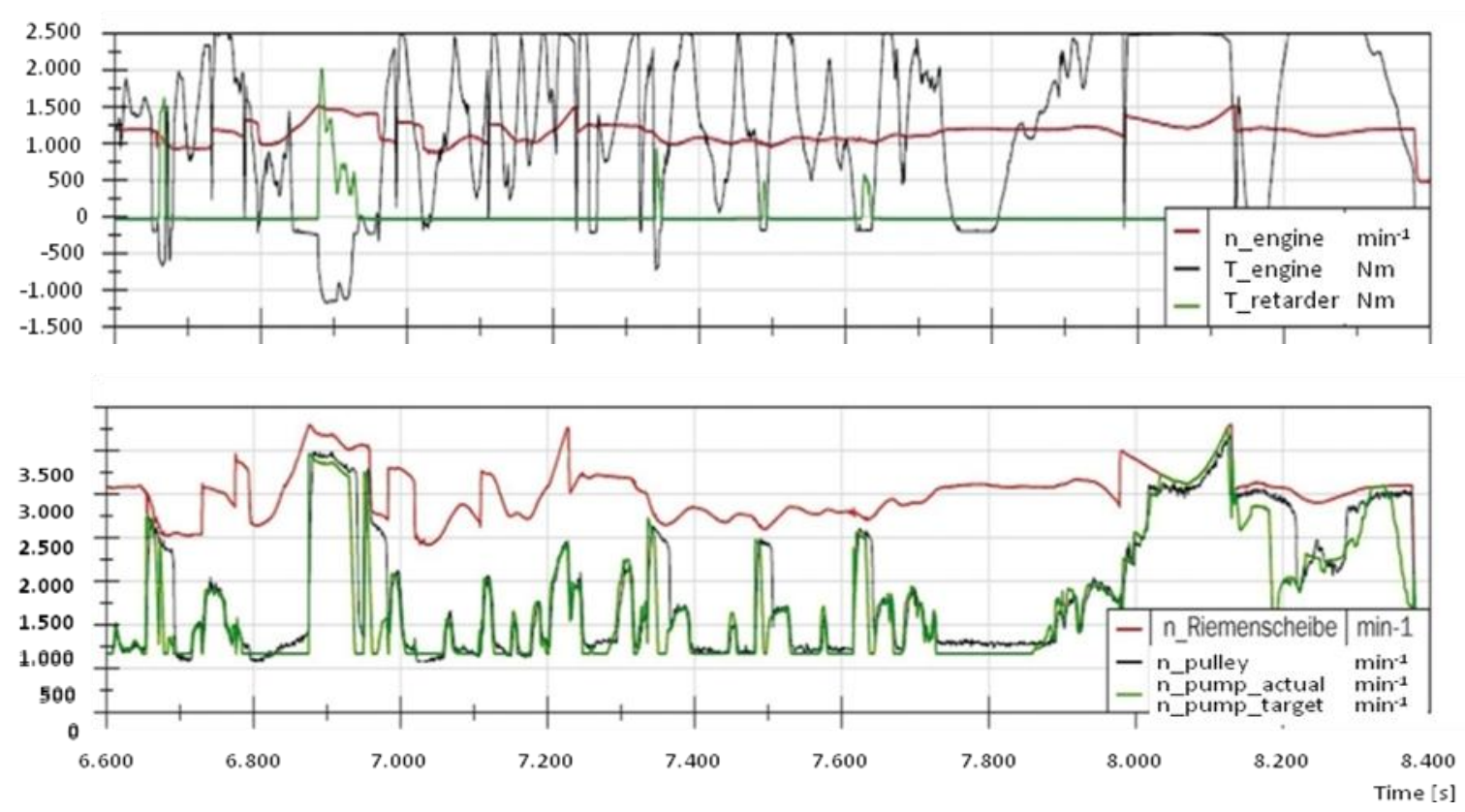

Figura 12 - Teste com veículo em campo

O potencial de reduzir a rotação da bomba foi confirmado em uma gama de condições de operação. Desvios maiores foram verificados apenas em áreas logo após condições de acoplamento completo, devido ao comportamento de histerese comum às embreagens viscosas. Mesmo com cargas dinâmicas, em muitas regiões de cargas médias, observa-se que um acionamento mínimo da bomba foi o suficiente, mostrando um alto potencial de economia de combustível.

\section{CONCLUSÃO}

A pressão para a redução nas emissões e no consumo de combustível vão continuar sendo relevantes nos próximos anos em função da evolução das regulamentações, o que demanda dos fabricantes de veículos e seus fornecedores a busca de soluções otimizadas e novas tecnologias relacionadas.

O gerenciamento térmico nos motores desempenha um papel importante para atender a estas demandas. $\mathrm{O}$ aumento da carga térmica dos motores e as suas implicações nos sistemas de arrefecimento requerem sistemas e componentes mais eficientes, e por consequência, uma demanda de 15 a $20 \%$ a mais de vazão de ar refrigerante necessária no sistema. Um dos segredos para evitar um aumento no consumo de combustível, e de obter até reduções significativas, está no controle eficiente da energia empregada.

Soluções de embreagem viscosa com controle eletrônico utilizado em ventiladores e bombas d'água mostram-se como um grande potencial. Comparados com os ventiladores de acionamento rígidos ou on/off existentes, o E-Visco apresenta reduções no consumo de 4,0\% e 1,0\% respectivamente. A bomba d'água de embreagem viscosa se abre também como um elevado potencial de economia de combustível para os veículos pesados, apresentando potencial de redução de $0,5 \%$ a $1,0 \%$ em relação ao acionamento rígido. A tecnologia E-Visco 
já faz parte da realidade Euro VI na Europa, mas ainda em países como China, Índia e Brasil, há apenas um pequeno número de aplicações em uso, onde é grande ainda soluções de acionamentos rígidos, on/off ou unidades Visco bimetálicos. No entanto, com a necessidade de atendimento as leis cada vez mais apertadas de emissões e redução de consumo, é fato de que o uso de controle eletrônico nas embreagens viscosas está se tornando uma tendência de mercado.

\section{REFERÊNCIAS}

[1] REGULATION (EC) No 595/2009 OF THE EUROPEAN PARLIAMENT AND OF THE COUNCIL of 18 June 2009. Resolution Official Journal of the European Union. June 2009

[2] O Impacto de Padrões Avançados para Combustíveis e Veículos na Mortalidade Prematura e Emissões: Brasil no Contexto Global. International Council on Clean Transportation (ICCT) Informativo Outubro 2013. Disponível em http://www.theicct.org/sites/default/files/ICCT_Briefing_BrazilHealth_20131001_PT.pdf

[3] PANTOW, Eberhard; BANZHAF, Matthias; EDWARDS, Simon. Thermal management for the reduction of emissions and fuel consumption in trucks. Local: editora, data. [4] CLOUDT, R.; WILLEMS, F.; VAN DER HEIJDEN. Cost and Fuel Efficient SCR-only Solution for post-2010 HD Emission Standards. SAE International 2009-01-0915 [5] SCHULTHEISS, Gerold; BANZHAF, Matthias; EDWARDS, Simon. ViscoWasserpumpe Bedarfsabhängige Regelung der Fördermengemanagement for the reduction of emissions and fuel consumption in trucks. MTZ 032012 